\title{
PERFIL DOS PROFESSORES DE ARTES PLÁSTICAS INGRESSANTES NA REDE MUNICIPAL DO RIO DE JANEIRO E SEU OLHAR SOBRE SUA INSERÇÃO PROFISSIONAL
}

\author{
PERFIL DE LOS PROFESORES DE ARTES PLÁSTICAS DE RECIÉN INGRESO EN \\ LA RED MUNICIPAL DE RIO DE JANEIRO Y SU MIRADA SOBRE SU INSERCIÓN \\ PROFESIONAL
}

\section{THE PROFILE OF VISUAL ARTS TEACHERS WHO HAVE RECENTLY JOINED THE RIO DE JANEIRO MUNICIPAL NETWORK AND THEIR VIEWS ON THEIR PROFESSIONAL INSERTION}

\author{
Thaís Spínola AFONSECA ${ }^{1}$ \\ Maria das Graças Chagas de Arruda NASCIMENTO ${ }^{2}$
}

RESUMO: Este artigo apresenta parte de uma pesquisa de mestrado que investigou o processo de inserção profissional de professores de Artes Plásticas (nomenclatura oficial) na rede pública municipal do Rio de Janeiro, a partir de 2016. O diálogo teórico é feito principalmente com Hurberman (2000) e Marcelo García (1999). Os instrumentos utilizados foram questionário e entrevistas semi-estruturadas. Os sujeitos da pesquisa foram 18 professores de Artes Plásticas ingressantes na rede entre os anos de 2016 e 2019. Foram tomadas para as análises as perspectivas dos próprios professores ingressantes. Os resultados indicam que os sujeitos são predominantemente mulheres jovens (20 a 40 anos), que possuem pós-graduação e que ingressaram com alguma experiência no magistério. As condições de trabalho dispararam como justificativa dos pensamentos de abandono da carreira. Foi notado que o apoio da direção e coordenação da escola ou a falta dele se mostrou fator preponderante na qualidade da inserção e desenvolvimento profissional dos docentes ingressantes. Observou-se ainda que, na busca por apoio, a maioria dos ingressantes recorre a professores conhecidos de Artes Plásticas que também sejam da rede para aliviar suas preocupações e angústias e compartilhar práticas.

PALAVRAS-CHAVE: Formação de professores. Ensino de arte. Inserção profissional.

RESUMEN: El trabajo que se presenta es un estudio resultado de un máster, que investigó el proceso de inserción profesional de los docentes de artes plásticas (nomenclatura oficial) en la red pública municipal de Río de Janeiro, en el año 2016. El diálogo teórico es hecho principalmente con Huberman (2000) y Marcelo García (1999). Los instrumentos utilizados fueron, un cuestionario y entrevistas semiestructuradas. Los participantes de la investigación fueron 18 profesores de artes plásticas recién ingresados en la red entre los años 2016 y 2019. Para el análisis de los datos se tiene en cuenta la perspectiva de los propios profesores

\footnotetext{
${ }^{1}$ Universidade Federal do Rio de Janeiro (UFRJ), Rio de Janeiro - RJ - Brasil. Doutoranda no Programa de PósGraduação em Educação (PPGE). ORCID: https://orcid.org/0000-0002-8902-3836. E-mail: spinnnola@gmail.com

${ }^{2}$ Universidade Federal do Rio de Janeiro (UFRJ), Rio de Janeiro - RJ - Brasil. Professora Associada da Faculdade de Educação, Departamento de Didática. Doutorado em Educação (PUC-Rio). ORCID: https://orcid.org/0000-0002-6334-4121.E-mail: mgcanascimento@gmail.com
} 
recién ingresados. Estos indican que los sujetos son predominantemente mujeres jóvenes (20 a 40 años), postgraduadas y que ingresaron con alguna experiencia en magisterio. Otro resultado a destacar, son las condiciones de trabajo que provocan procedentes pensamientos de abandono de la carrera. Así como, el apoyo por parte de la dirección y coordinación escolar, que muestran que es un factor principal que influye en la calidad de la inserción y el desarrollo profesional de los docentes recién ingresados. Del mismo modo, se observó que los recién ingresados buscan apoyo en docentes de la misma àrea y de la misma red con el fin de compartir sus preocupaciones, angustias y la práctica educativa.

PALABRAS CLAVE: Formación de professores. Enseñanza de arte. Inserción professional.

ABSTRACT: The work presented is a study resulting from a master's degree, which investigated the process of professional insertion of Visual Arts teachers (Artes Plásticas as the official nomenclature) in the municipal public network of Rio de Janeiro in 2016. The theoretical framework is based mainly on Huberman (2000) and Marcelo Garcia (1999). The instruments used were a questionnaire and semi-structured interviews. The participants of the research were 18 Visual Arts teachers who had recently joined the network between 2016 and 2019. For the analysis of the data, the perspective of the newly admitted teacher themselves was taken into account. They indicate that the subjects are predominantly young women (20 to 40 years old), postgraduates who entered with some experience in teaching. Another result to be highlighted, is the working conditions that provoke thoughts of abandoning the career. Also, support from school management and coordination has proven to play a major role in influencing the quality of insertion and professional development of newly-hired teachers. Similarly, it was observed that newcomers seek support from other Visual Arts teachers who work in the same network in order to ease their concerns and anxieties and share educational practices.

KEYWORDS: Teacher training. Art teaching. Professional insertion.

\section{Introdução}

Este artigo é fruto de uma pesquisa vinculada a um programa de pós-graduação strictu sensu de uma universidade pública localizada na cidade do Rio de Janeiro, parcialmente financiada pelo Conselho Nacional de Desenvolvimento Científico e Tecnológico - CNPq. Essa pesquisa se debruçou sobre o processo de inserção profissional de professores de Artes Plásticas, ingressantes na rede pública municipal do Rio de Janeiro a partir do último concurso público (2016), buscando desenhar um perfil desses profissionais, qualificar seus processos de inserção profissional segundo suas próprias impressões e investigar a quais estratégias de formação no exercício de seu trabalho eles costumam recorrer. Neste artigo focaremos nos achados sobre o perfil desses sujeitos e suas percepções sobre sua inserção profissional.

Ao assumirem o cargo de docente em escolas públicas de educação básica no país, os licenciados em Artes Visuais encontram diferentes realidades e condições de trabalho, 
podendo ser esperado que ensinem outras linguagens artísticas, como música e teatro, além da sua especialidade - prática conhecida com polivalência; podem assumir turmas de educação infantil, dos anos iniciais ou finais do Ensino Fundamental ou em um, dois ou nos três anos do Ensino Médio. Conforme o contexto, no que se refere à carga horária semanal de aulas, se depararam normalmente com um ou dois tempos semanais de $50 \mathrm{~min}$ com seus alunos e, por conta disso, são responsáveis por numerosas turmas e diários de classe. Isso acarreta que, muitas vezes, um único professor de Artes dê aula para todas ou quase todas as turmas da escola, inviabilizando o contato com colegas da mesma disciplina na escola, o que pode atrapalhar o planejamento conjunto e a formação continuada entre pares. Podem ter sua disciplina interpretada pela comunidade escolar como recreação ou decoração; podem ter ao seu dispor salas de artes ou atuarem em salas de aula comuns; podem ter armário com material artístico abundante ou não; podem lecionar em uma ou mais escolas de iniciativa pública ou privada. Enfim, havendo ainda outras variáveis em jogo, reconhecemos que a inserção nessa carreira pode correr de modo mais ou menos difícil para quem está dando seus primeiros passos nessa profissão.

Esse processo de inserção profissional, que pressupõe uma intensidade de descobertas e sentimentos, não é tão diferente do que se tem observado com docentes principiantes de outras áreas (MARCELO GARCÍA³ , 1999; COCHRAN-SMITH, 2014). Porém, em virtude desses heterogêneos contextos de atuação e das peculiaridades intrínsecas ao ensino artístico, esse trabalho se interessou em aprofundar o olhar às especificidades dos docentes de Artes Plásticas recém-ingressos nessa que é a maior rede municipal pública da América Latina, procurando entender quem são esses sujeitos e como têm lidado com o que encontraram.

Cabe evitarmos uma confusão de denominação, esclarecendo que o termo Artes Visuais costuma às vezes ser igualado a Artes Plásticas, porém pontuamos que a última é uma nomenclatura um pouco mais antiga e limitante, pois contempla stricto sensu a produção artística realizada apenas com materiais plásticos, manipuláveis, não abrangendo as artes digitais e audiovisuais, por exemplo. Por convenção reivindicada pela Federação dos ArteEducadores do Brasil (FAEB), homologada no Parecer CNE/CEB N ${ }^{0}: 22 / 2005$, oficializou-se o nome Artes Visuais, como consta também nos Parâmetros Curriculares Nacionais de 1997. A rede pública carioca inova frente a outras redes por realizar concursos específicos para seus docentes conforme a linguagem artística, contando com professores de Educação Musical,

\footnotetext{
${ }^{3}$ Neste artigo, o autor Carlos Marcelo será referenciado como Marcelo García, respeitando a forma de citação que o próprio autor utiliza em seus textos.
} 
Artes Cênicas e, finalmente, Artes Plásticas, optando por esse termo oficialmente, por isso o seu uso recorrente neste trabalho.

Dessa maneira, esse artigo está organizado de modo a apresentar primeiramente as escolhas metodológicas, a interface com a literatura sobre inserção profissional e o ensino de artes e os resultados da pesquisa no que se refere ao perfil desses ingressantes e como se expressaram acerca da entrada na rede.

\section{Aspectos metodológicos, a inserção profissional e o ensino de artes}

No que se refere ao percurso metodológico, a opção foi pela convergência de dados quantitativos e qualitativos, utilizando, em primeiro lugar, um questionário com o intuito de desenhar um perfil preliminar dos docentes (sexo, idade, formação, experiência prévia, tipo de vínculo, região da escola que atua etc.), capturando indícios sobre suas identidades e relações com suas escolas, e, em seguida, entrevistas semiestruturadas para o aprofundamento das questões expostas. O projeto de pesquisa foi apreciado pelo Comitê de Ética em Pesquisa (CEP) via Plataforma Brasil e, após a aprovação, foi iniciado o trabalho em campo.

Em busca dos sujeitos para a pesquisa, foram consultados os Diários Oficiais em que se oficializavam as posses dos candidatos do último concurso para docentes de Artes Plásticas para o município do Rio de Janeiro (Edital SMA nº 93, de 2016).

Foi possível enumerar 67 professores desse modo, porém a coleta de dados só pode ser iniciada, em 2019, a partir da localização de um grupo de WhatsApp voltado especificamente para a comunicação entre os candidatos do concurso. Nesse grupo constavam somente 57 integrantes, dentre docentes já convocados e docentes que aguardavam sua chamada.

Após a explicação da pesquisa e firmado o compromisso com o sigilo das identidades dos participantes, foi feito, por esse aplicativo, o convite para dela participarem, respondendo o questionário online (GoogleForms) que seria disponibilizado. Cinco integrantes desse grupo avisaram, imediatamente, que não haviam sido convocados ainda e, portanto, não pertenciam ao público-alvo da pesquisa. Sendo assim, dentre os 57 participantes do grupo, somente 52 estariam, presumivelmente, aptos a participarem, visto que nem todos responderam ao convite, sendo possível inferir que, além desses 5 docentes que não haviam ingressado efetivamente na rede, poderia haver outros professores nessa situação.

O questionário foi composto predominantemente por 15 questões fechadas e 2 abertas. Sua organização foi pensada para cobrir quatro seções: perfil, experiência profissional docente, percepção sobre inserção na rede e estratégias de formação. De início foram 
requisitados o nome, endereço eletrônico, idade, curso e ano de graduação e a existência de alguma pós-graduação. Em sequência, as questões se dedicavam a saber se havia experiência como docente de Artes anterior à entrada na rede, o tempo dessa experiência em anos e em que espaços ela foi adquirida: na iniciativa pública, privada, espaços de ensino não formal (educativos de museus, centros culturais, projetos ou ONGs) e/ou outras modalidades que eles pudessem acrescentar. Para mapear parte das condições de trabalho dos ingressantes, eles deviam responder em quantas escolas atuavam, à qual Coordenadoria Regional de Educação $(\mathrm{CRE})^{4}$ pertenciam e se haviam permanecido na mesma escola desde que tinham iniciado nessa matrícula. Foram questionados ainda se haviam pensado em pedir exoneração nos primeiros meses de trabalho, tendo que justificar. Em seguida encontravam questões de múltipla escolha em que deveriam avaliar o seu processo de inserção nas escolas/turmas/rede, o apoio recebido na escola/rede e em que grau se consideravam professores de Artes Plásticas adaptados ao seu trabalho.

É importante frisar que após o intervalo concedido de duas semanas, retornaram 18 questionários respondidos, todos válidos e adequados em sua integralidade. Dentre os respondentes, somente 10 se mostraram efetivamente recém-ingressantes, ou seja, entraram, a partir de 2016, na rede municipal pela primeira vez. Uma parte dos convocados (oito) já era docente de Artes Plásticas da própria rede pública municipal, tendo prestado concurso novamente para mudar o regime de trabalho (de 16h/semanais para 40h/semanais), conforme política que vem sendo implementada desde 2011, ou acumular com uma nova matrícula, o que é permitido no magistério, totalizando 56h/semanais de trabalho. No caso dos sujeitos dessa pesquisa, cabe ressaltar que o concurso a que se submeteram em 2016 era para 40h semanais. De modo a aproveitar todos os dados levantados e organizar o volume de informações, os sujeitos foram divididos em dois grupos: dos reingressantes ( 8 pessoas) e dos recém-ingressantes (10 pessoas).

No desenho inicial da pesquisa, a intenção era, após o questionário, realizar as entrevistas agrupando os recém-ingressantes principiantes na carreira docente de maneira que suas impressões sobre a entrada na rede se fundissem com suas impressões sobre os primeiros passos na profissão. Porém, apenas uma das iniciantes aceitou ser entrevistada. Desse modo, como a percepção de apoio e de adaptação ao novo ambiente e condições de trabalho se mostrou heterogênea como um todo, suspeitou-se sobre a influência da experiência docente anterior como uma variável que poderia se mostrar relevante.

\footnotetext{
${ }^{4}$ Instância administrativa da Secretaria Municipal de Educação que é responsável por um conjunto de unidades escolares divididas por localidade, abrangendo bairros adjacentes da cidade. Atualmente existem 11 diferentes coordenadorias regionais de educação na rede pública carioca.
} 
Portanto, os 18 questionários respondidos foram categorizados por tempo de experiência profissional anterior ao ingresso na rede. A partir dessa classificação, foram selecionados 3 docentes para a realização de entrevistas semiestruturadas que focaram na descrição e avaliação de seus processos de inserção: uma docente com nenhuma experiência anterior, uma com até 5 anos e outro com mais de 10 anos de experiência docente anterior. Por seus perfis e por partilharem uma rede de contatos em comum com uma das pesquisadoras, a iniciante e os dois outros docentes selecionados concordaram em participar. Os encontros presenciais individuais para as entrevistas se deram nos dias e locais de concordância de ambas as partes, com a leitura e assinatura do Termo de Consentimento Livre e Esclarecido (TCLE), sendo gravadas em áudio.

Essa classificação por anos de experiência prévia esteve amparada por critérios extraídos das reflexões de Huberman (2000) sobre os ciclos de vida profissional de professores. Foi entendido que a experiência profissional anterior, no caso, poderia influenciar as percepções sobre como se dá o ingresso dos professores na rede pública da cidade do Rio de Janeiro. O roteiro de entrevista previa um aprofundamento das perguntas do questionário, abrindo-as para uma conversa e colhendo impressões mais detalhadas sobre o que já havia sido declarado.

\section{Alguns pontos de partida}

Compreendemos aqui a formação docente como um processo contínuo, inaugurado pela experiência pré-profissional como aluno, seguido pela profisssionalização na formação inicial, pela fase de iniciação ao trabalho e pela formação permanente (MARCELO GARCÍA, 1999). Sendo assim, dedicamos nossa atenção à etapa que corresponde à transformação do estudante em professor e à adaptação ao contexto real de atuação, mais conhecido como período de inserção profisssional.

Ao discorrer sobre os ciclos de vida profissional dos docentes, Huberman (2000) se refere à análise de Simon Veenman (1984), que identifica essa fase como um "choque de realidade", quando há uma preocupação em sobreviver à profissão, intensa aprendizagem via ensaio e erro e o predomínio do valor prático, o que faz com que os principiantes tenham problemas em relacionar as teorias e princípios estudados na faculdade com os seus dilemas. As dificuldades e descobertas advindas da realidade escolar com a qual o professor iniciante se depara são experimentadas intensamente. Para o autor, a duração dessa fase até a estabilização do docente pode ser estimada entre 3 e 5 anos (HUBERMAN, 2000). Esse 
intervalo, no entanto, pode variar bastante em cada caso. É importante destacar que, ao nosso ver, o educador pode experimentar um processo de inserção toda vez que se vê em uma nova realidade de trabalho: uma nova rede de ensino, escola, turma, função ou condição de trabalho.

De acordo com a literatura (HUBERMAN, 2000; NÓVOA, 2007; VAILLANT; MARCELO GARCÍA, 2012), a qualidade desse momento determina, em grande parte, o grau de adesão à carreira/cargo, pois consoante à existência prolongada de apoio e familiarização com a cultura institucional, essa transição pode se dar de modo suave, facilitando o desenvolvimento profissional enquanto o docente ainda se sente um novato.

Nesse sentido, a literatura tem destacado a importância de programas de indução profissional dirigidos aos docentes que iniciam a carreira. Tais programas incluem ações sistemáticas, focadas em favorecer a troca de saberes entre professores iniciantes e experientes, orientação e acompanhamento do processo de inserção profissional.

Nesse contexto, apontamos a importância das ações voltadas para o processo de inserção profissional considerar a especificidade da disciplina ou nível/modalidade à qual o professor se dedica, visto que os desafios e incertezas vivenciados, que são indissociáveis da sua realidade de ensino, requerem, muitas vezes, suporte de pessoas que (re)conheçam intimamente as questões pedagógicas e ambientais que venham a surgir. Como todos os professores que ingressam na carreira, os professores de Artes Visuais se deparam com uma grande variedade de condições de trabalho. Contudo, por terem uma carga horária de aula pequena, em geral 1 ou 2 aulas por semana em cada turma, esses professores experimentam, com frequência, a sensação de isolamento pela ausência de colegas da mesma especialidade no seu turno ou mesmo em toda a escola. Tal situação, além de refletir uma certa desvalorização de sua disciplina frente a outras, faz com que esses professores tenham um número excessivo de turmas de várias idades e séries, algumas vezes em mais de um estabelecimento, precisando negociar materiais e espaços para uso artístico e o exercício ou não da polivalência.

Nesse cenário, a cidade do Rio de Janeiro desponta como um laboratório de políticas públicas educacionais voltadas para professores em situação de inserção profissional, uma vez que sua Secretaria de Educação (SME/Rio) conta, desde 2012, com um centro de recepção e formação continuada de seus professores, a Escola de Formação Paulo Freire (EPF).

Recentes estudos têm apontado uma tradição de escassos e pontuais programas de indução profissional a professores no Brasil (ANDRÉ, 2013; MIRA, 2018), sendo comum que os principiantes sejam alocados nas "piores" turmas e escolas, sob expectativas idênticas 
às de professores experientes. A indução funcionaria, nesse momento inicial da carreira, como uma logística de acolhimento, assessoria e formação afinada com as necessidades e circunstâncias vividas pelos profissionais inexperientes no serviço. Marcelo García (1999), citando Valli (1992, p. 132), afirma que:

Os problemas que mais ameaçam os professores principiantes são a imitação acrítica de condutas observadas noutros professores; o isolamento dos seus colegas; a dificuldade em transferir o conhecimento adquirido na sua etapa de formação e o desenvolvimento de uma concepção técnica do ensino.

Em vários países, a indução faz parte do percurso formativo do candidato que deseja integrar o quadro docente das escolas públicas, a fim de minimizar o número de desistências/abandono. Em alguns casos, o programa de indução tende a se confundir com estratégias avaliativas do período de estágio probatório. Analisando experiências com programas de indução, que podem ter múltiplos formatos e extensão, Vaillant e Marcelo García (2012) citam Smith e Ingersoll (2004, p. 706), para afirmarem que "o fator mais sobressalente [para o docente iniciante] foi dispor de um mentor de sua mesma especialidade, ter tempo para planejar junto com outros docentes da mesma matéria e fazer parte de uma rede externa".

Ao nosso ver, torna-se urgente investigar o assunto e averiguar as condições de tantos professores de Artes Visuais no Brasil que estão sobrevivendo, desenvolvendo dispositivos de formação ou em vias de desistir da carreira docente, devido à crise inicial típica do momento de inserção profissional. Para além dos desafios enfrentados pelos professores no momento em que ingressam no magistério, existe ainda, no Brasil, um fator que pode agravar as condições de trabalho desses professores: o alto número de professores não especialistas responsáveis pelas aulas de Artes nas escolas do país, devido à ausência de docentes específicos, ainda que computemos a ocupação das vagas por professores com licenciatura em alguma linguagem artística. De acordo com o Censo Escolar de 2017, o percentual de professores de Artes com formação específica atuando nos anos iniciais do Ensino Fundamental é 58,7\%, nos anos finais apenas 31,5\% e no ensino médio 41,1\% (INEP, 2017).

Esse panorama se arrasta como traço de uma história do ensino de artes no Brasil (BARBOSA, 2016), cujo exercício docente na educação básica foi profissionalizado muito recentemente. A partir de Lei 5692, que modificou a estrutura de ensino do país em 1971, no contexto da ditadura militar, se estabeleceu a atividade Educação Artística nas escolas, agregando artes plásticas, teatro e música ao seu currículo. Para ministrar a atividade Educação Artística era necessário possuir um diploma de graduação. Para resolver essa 
questão, o governo oficializou apressadamente os cursos de Licenciatura Curta em Educação Artística, que preconizavam uma formação polivalente, tinham a duração de 2 anos, currículo compacto e disciplinas fragmentadas e rasas. Uma opção precursora da Escola de Belas Artes da UFRJ e disseminada para outras universidades públicas da época foram os cursos de Licenciatura Plena, onde os candidatos poderiam continuar seus estudos com habilitação na linguagem escolhida, com duração de 4 anos. O ensino das Artes havia ganhado lugar cativo nas escolas, mas em uma situação que lhe reservava fragilidade:

Não sendo considerada matéria e não tendo espaço fixo no horário de aulas, a Educação Artística é relegada a um plano secundário, sendo utilizada de maneira aleatória para outros objetivos, quase sempre morais e/ou de suporte para outras disciplinas, que não o de ensinar arte (PIMENTEL, 1999, p. 96).

A concepção da arte como horário de lazer também se consagrou, resultando no conhecido laissez-faire ("deixai fazer"), em que a aula se torna um tempo de livre expressão sentimental, sem qualquer tipo de orientação. No final da década de 1970 e por toda a década de 1980 a emergência de reivindicações por direitos democráticos ressoou e houve mudanças com a promulgação da Lei de Diretrizes e Bases da Educação de 1996 (Lei 9.394/96), que determinou a Arte como disciplina obrigatória na educação básica, ou seja, reconheceu-a como campo de conhecimentos com conteúdos específicos importantes. Isso foi explicitado logo depois nos Parâmetros Curriculares Nacionais (PCN) de 1997, que declararam no segmento Artes Visuais (denominação que engloba as artes plásticas, as artes gráficas, o vídeo, o cinema, a fotografia e as novas tecnologias) evidente adesão à Proposta Triangular de Ana Mae Barbosa, princípio pedagógico que se popularizou e que prevê uma articulação crítica entre três dimensões da produção artística: contextualização (indo além da história da arte), experimentação (fazer) e apreciação (leitura de obra).

\section{O perfil e a inserção profissional dos professores de Artes Plásticas}

Aqui trataremos dos resultados da pesquisa no que se refere ao perfil dos sujeitos docentes de Artes Plásticas que participaram da pesquisa e às impressões sobre seus processos de inserção profissional na rede municipal do Rio de Janeiro.

Importante salientar que as oito reingressantes, apesar de já serem professoras da própria rede, passaram, de fato, por todos os passos que são previstos para os que entram nela pela primeira vez: participação em concurso público com fases que exigiam prova escrita, curso de formação na Escola Paulo Freire, prova aula, prova de títulos, acolhimento de dois 
dias na Escola Paulo Freire, acolhimento promovido pela CRE designada, escolha das escolas por ordem de classificação e, em princípio, 2 dias de acolhimento na escola. As etapas que envolvem o processo seletivo foram vivenciadas de forma obrigatória por todos os sujeitos da pesquisa. Contudo, as etapas que caracterizam o momento de acolhimento, após a posse no cargo, foram vivenciadas de forma distinta pelos professores que fizeram parte da pesquisa.

Todas as reingressantes eram mulheres e, dentre os dez recém-ingressantes, oito eram mulheres e dois homens. Os/as dezoito docentes que responderam ao questionário possuíam a formação mínima específica exigida para o cargo: licenciatura em Educação Artística/Artes Plásticas/Artes Visuais; a maioria era jovem (20 a 40 anos), tinha pós-graduação e já possuía experiência no ofício, tanto na iniciativa privada quanto na pública.

Como dito anteriormente, três desses docentes foram entrevistados/as: a professora iniciante Alba, 36 anos, que, em segunda graduação, concluída em 2016, formou-se em licenciatura em Educação Artística. Colou grau em janeiro e foi convocada pela SME em fevereiro. No período da entrevista, em 2019, estava alocada somente em uma escola, no bairro de Santa Cruz, um bairro afastado do centro, na Zona Oeste da cidade, onde atuava desde seu ingresso na rede. Ela afirmou ser a única professora de Artes Plásticas da unidade e lecionava nos anos iniciais do Fundamental. Confessou com firmeza que pretendia abandonar a carreira na rede muito em breve, pois se sentia "enxugando gelo", e vinha se planejando para isso.

A professora Beatriz, 30 anos, licenciou-se em Artes Plásticas em 2013 e estava cursando uma pós-graduação lato sensu em 2019, quando se deu a entrevista. Quando ainda estava em seus últimos períodos da faculdade começou a dar aulas em uma escola particular para os anos finais do Fundamental. Depois, atuou por mais 4 anos em uma outra escola particular, ensinando nos anos iniciais do Fundamental. Ingressou na rede pública municipal em junho de 2019, atuando em duas escolas de turno integral ${ }^{5}$, localizadas na mesma rua, dentro de uma favela em Bangu. Em ambas, ministrava aulas para os anos iniciais do Fundamental. Segundo ela, nunca teve "aquele sonho de se formar e dar aula no município", tendo sido uma questão de necessidade econômica. Pela realidade de seus alunos e do entorno, de extrema violência e vulnerabilidade social, ela estava achando difícil se adaptar e afirmou que nem vislumbrava uma adaptação a esse contexto. Descreveu recepções bastante

${ }^{5}$ Desde 2011 a SME Rio investe na proposta de ampliar o número de escolas da rede que trabalham com o que chamam de educação integral em tempo integral, instituindo os turnos únicos; ou seja, os mesmos alunos que entram pela manhã permanecem até o meio da tarde. A maioria das escolas, no entanto, ainda funciona com turnos parciais. Os turnos parciais são uma solução para atender mais alunos em uma mesma escola. 
díspares nas duas escolas em que trabalha, preferindo a relação colaborativa que encontrou na escola de complementação à relativa solidão de sua escola de origem.

O professor Caio, 40 anos, formado com uma licenciatura em História da Arte, iniciou sua experiência como docente em 2006, antes mesmo de se graduar. Trabalhou em creches com musicalização infantil (formação autodidata em música) e em escolas particulares dando aulas de Artes Plásticas. Atuou como arte-educador em um grande centro cultural e como professor substituto no Colégio Pedro II. Em fevereiro de 2019 foi chamado para ser professor de Artes no município de Niterói, onde permanece. Em junho foi a vez de o município do Rio de Janeiro convocá-lo. Ao ser entrevistado trabalhava em duas escolas de turno parcial, com turmas dos anos finais do Ensino Fundamental. Considerou seu processo de inserção uma "boa surpresa", tendo encontrado um acolhimento e infraestrutura ótimos na sua escola de origem, contrariando as expectativas baixas que tinha pelas experiências compartilhadas por outros convocados.

Sobre o cotidiano de trabalho foi possível verificar que a maioria das reingressantes atua em mais de 1 escola, ao contrário do que foi exposto pelos recém-ingressantes. Uma suspeita que ajuda a explicar esse dado reside no acúmulo de matrículas na mesma rede por parte das reingressantes que, logicamente, devem atuar em mais de uma escola, juntando à sua antiga escola o novo local de trabalho escolhido no último concurso. Das oito reingressantes, somente duas atuavam em apenas uma escola, enquanto esse número subiu para sete dentre os dez recém-ingressantes.

Também é comum um professor de Artes Plásticas, com um regime de trabalho de $40 \mathrm{~h}$ semanais, o que é o caso dos sujeitos dessa pesquisa, não conseguir completar sua carga horária em apenas uma escola e necessitar complementar em outra. Essa situação se agrava entre professores das disciplinas que possuem menor carga horária na estrutura curricular dos estudantes, como é o caso das Artes Plásticas. Não se pode deixar de apontar que a condição mais desejável residiria em trabalhar em uma única escola.

Mais do que a metade dos dez recém-ingressantes pensaram em pedir exoneração nos primeiros meses de trabalho, um quadro preocupante para a rede. As condições de trabalho dispararam como justificativa dos pensamentos de desistência e compreendem aspectos como o desgaste resultante do elevado número de turmas, turmas lotadas, falta de material e espaço próprios para o trabalho em Artes Visuais. Esse ponto foi considerado tão crítico que o total dos ingressantes, dezoito docentes, concordou em classificá-lo como a maior dificuldade sentida durante a inserção profissional. O que se viu é que, na falta de recursos materiais para 
as aulas, esses professores acabam por comprarem, eles mesmos, os materiais que consideram imprescindíveis para suas aulas.

Essa situação não deve ser encarada com naturalidade, pois desnuda uma face brutal da estrutura educacional que, por vezes, se mostra incapaz de prover as necessidades didáticopedagógicas das escolas, bem como de proporcionar um contexto que favoreça o desenvolvimento profissional docente. Escolas perdem, estudantes perdem e os profissionais dispostos a investir na carreira optam, muitas vezes, por terem que escolher entre sua qualidade de vida e seu trabalho. Quanto a isso, Signorelli e Matsuoka (2015) afirmam que a grande maioria dos estudos que tratam do início da docência retratam as dificuldades que os professores enfrentam no início da carreira ao se defrontarem com intensas situações que vão colocando em xeque seus saberes, crenças, princípios educativos e conhecimentos formulados durante a formação inicial que, neste momento, parecem não muito valiosos.

Os primeiros anos de exercício profissional são fundamentais para o futuro profissional dos professores, chegando a serem definidores da permanência ou não na profissão. Assinalam ainda, citando Papi e Martins (2010), que:

[...] o início da carreira pode ser fácil ou difícil, simples ou complexo, e isso dependerá das condições encontradas pelos iniciantes no local de trabalho, das relações que estabelecem com outros colegas e do apoio que recebem nessa etapa da carreira profissional. (SIGNORELLI; MATSUOKA, 2015, p. 37256)

Há variações, mas a maioria das reingressantes descreveu seu processo de inserção como muito difícil. É reforçada aqui a ideia de que a entrada em um novo contexto de trabalho, ainda que haja experiência na docência, inclusive na mesma rede, funciona como uma nova inserção que pode ser tão complexa quanto a de um principiante na carreira. Pode indicar ainda que a rede e/ou a gestão da escola, por reconhecerem que se tratavam de docentes que já pertenciam à rede, entendiam que não haveria necessidade de maiores cuidados com a recepção e o acompanhamento desses profissionais.

Surpreendentemente, os recém-ingressantes perceberam, em geral, sua inserção como razoável. Numa leitura geral, foi este o grupo que considerou seu processo mais facilitado. Uma possível leitura desse dado é que as suas expectativas sobre a inserção na rede tenham sido superadas pelo ambiente favorável e pelo apoio encontrados na maioria das escolas para onde foram designados.

Todos os recém-ingressantes que admitiram ter tido uma inserção com pouca dificuldade indicaram ter encontrado um ótimo apoio na rede e/ou na escola. Os que 
consideraram seu processo de inserção como razoável descreveram o apoio detectado como satisfatório ou mediano. Nos processos de inserção com muitas dificuldades, o apoio foi classificado como insatisfatório ou mediano. Portanto, a relação se mostra evidente: quanto mais os ingressantes se sentem apoiados por diretores, coordenadores e outros professores, melhores se tornam os seus processos de inserção à carreira docente na rede. $\mathrm{O}$ contrário também parece ser verdadeiro, podendo inclusive culminar no abandono da profissão.

Quanto a esse aspecto, Ens et al. (2014) pontuam como a docência historicamente tem sido vista como uma carreira de pouco prestígio no país e, em contexto de reivindicação de maior profissionalização a partir dos anos de 1990, ainda se encontra entre o discurso de valorização e políticas públicas que timidamente investem nessa direção ou até a contradizem. Ao pesquisar as representações sociais de professores que atuavam entre 5 e 10 anos nos anos finais do Ensino Fundamental sobre a permanência ou não na profissão, 80\% declararam que continuariam no magistério (ENS et al., 2014).

No entanto, ao investigar as razões que levavam uma porção dos docentes a considerarem a evasão, foi destacada a frágil formação diante da sobreposição de funções requeridas em serviço, bem como a baixa remuneração salarial, a desvalorização social da profissão, a indisciplina dos alunos, as condições de trabalho e, finalmente, a falta de participação dos responsáveis na vida escolar.

Assim, consideramos preocupante a forma como a questão da permanência ou não na profissão professor vem se consolidando, pois a representação que os grupos sociais têm acerca dos professores (pais, alunos etc.) confunde-se com as representações dos próprios professores em relação à profissão docente, o que tem definido o baixo índice de busca pelos cursos de formação de professores (ENS et al., 2014, p. 517).

Os docentes que pretendiam permanecer na profissão justificaram seu posicionamento por conta do vínculo afetivo formado com os alunos e pela finalidade da profissão, percebida como missão. Esse panorama parece enfatizar, além de uma visão idealista da docência, a importância da socialização profissional e estabelecimento de laços no ambiente de trabalho, que os faz inclusive superar dificuldades estruturais e econômicas da carreira.

É nesse sentido que Tardif e Raymond (2000) enfatizam o quanto se tornar professor significa um processo de conversão ao longo do tempo, que inclui necessariamente a socialização profissional e a sensação de pertencimento à categoria. Para os professores iniciantes ou recém-chegados a um novo ambiente de trabalho, uma recepção e tratamento calorosos e solidários, logo de início, facilitam a inserção e adequação à profissão. 
A carreira é também um processo de socialização, isto é, um processo de marcação e de incorporação dos indivíduos às práticas e rotinas institucionalizadas das equipes de trabalho. Ora, essas equipes de trabalho exigem que os indivíduos se adaptem a essas práticas e rotinas, e não o inverso. Do ponto de vista profissional e da carreira, saber como viver numa escola é tão importante quanto saber ensinar na sala de aula. Nesse sentido, a inserção numa carreira e o seu desenrolar exigem que os professores assimilem também saberes práticos específicos aos lugares de trabalho, com suas rotinas, valores, regras etc. (TARDIF; RAYMOND, 2000, p. 217)

Quanto à avaliação do apoio recebido, foi notado que o apoio da direção e coordenação da escola ou a falta deles se mostraram fatores preponderantes na qualidade da inserção e desenvolvimento profissional dos docentes ingressantes. $\mathrm{Na}$ busca por apoio, a maioria dos ingressantes recorre também a professores conhecidos de Artes Plásticas que também sejam da rede para aliviar suas preocupações e angústias e compartilhar práticas.

\section{Considerações finais}

Desse modo, foi possível concluir que não é apenas uma nova realidade ou público que o ingressante enfrenta, mas todo um novo ambiente de trabalho, o que parece sugerir que mesmo com experiência prévia na carreira e na própria rede, o processo de entrada em uma nova escola a partir de uma nova matrícula gera ansiedades e inseguranças que podem ser amenizadas a partir de um sistema de apoio pensado para receber e orientar esses docentes dentro e no dia a dia da escola, afim de que se adaptem com confiança e, após esse período de transição, caminhem de maneira mais autônoma e independente.

No entanto, esse cuidado, quando se faz presente, costuma se dar de modo espontâneo e fluido, pouco institucionalizado. Ainda que não se caracterize como um suporte sistemático, esse clima institucional acolhedor parece influenciar diretamente na satisfação do ingressante com o trabalho. Quando ausente, as frustrações tendem a se acumular e o docente ingressante procura meios alternativos de apoio para se estabelecer na carreira, podendo ser bem-sucedido ou não.

Esse panorama indica que são necessárias maiores atenções ao acolhimento e apoio locais, especialmente os disponibilizados pela coordenação e direção das escolas que recebem professores ingressantes. Um clima institucional agradável e confortável, garantido por laços interpessoais e profissionais retroalimentados, parece quase garantir maior satisfação e desenvolvimento profissional do docente que está dando seus primeiros passos dentro de alguma escola dessa gigante e heterogênea rede que é a pública carioca. 


\section{REFERÊNCIAS}

ANDRÉ, M. Políticas de apoio aos docentes em estados e municípios brasileiros: dilemas na formação de professores. Educ. rev., Curitiba, n. 50, p. 35-49, dez. 2013. Disponível em: http://www.scielo.br/scielo.php?script=sci_arttext\&pid=S0104$40602013000400004 \& \operatorname{lng}=$ en\&nrm=iso. Acesso em: 18 jul. 2020.

BARBOSA, A. M. (org.). Arte-educação no Brasil. São Paulo. Editora Perspectiva, 2016.

COCHRAN-SMITH, M. "Learning to Teach over Time: Two Teachers, Two Paths". In: CONGRESSO INTERNACIONAL SOBRE PROFESSORADO PRINCIPIANTE E DESENVOLVIMENTO PROFISSIONAL, 4., 2014, Curitiba. Anais [...]. Curitiba: UTFPR, 2014.

ENS, R. T. et al. Evasão ou permanência na profissão: políticas educacionais e representações sociais de professores. Revista Diálogo Educacional, v. 14, n. 42, p. 501-523, jul. 2014. Disponível em: https://periodicos.pucpr.br/index.php/dialogoeducacional/article/view/6698. Acesso em: 18 jul. 2020.

HUBERMAN, M. O ciclo de vida profissional dos professores. In: NÓVOA, A. (org.). Vidas de professores. 2. ed. Porto: Porto, 2000.

INEP. Instituto Nacional de Estudos e Pesquisas Educacionais Anísio Teixeira. Notas Estatísticas do Censo Escolar 2017. Brasília: MEC, 2017.

MARCELO GARCÍA, C. Formação de professores: para uma mudança educativa. Porto Editora, 1999.

MIRA, M. M. Inserção profissional docente: sistematização de princípio e indicadores para melhoria desse processo. 2018. Tese (Doutorado) - Pontifícia Universidade Católica do Paraná, Curitiba, 2018. Disponível em:

https://archivum.grupomarista.org.br/pergamumweb/vinculos//00006c/00006c89.pdf. Acesso em: 18 jul. 2020.

NÓVOA, A. Desafios do trabalho do professor no mundo contemporâneo. (Livreto). São Paulo: SIMPRO, 2007. Disponível em:

http://www.sinprosp.org.br/arquivos/novoa/livreto_novoa.pdf. Acesso em: 18 jul. 2020.

PIMENTEL, L. G. Limites em expansão: licenciatura em artes visuais. Belo Horizonte, C/Arte, 1999.

SIGNORELLI, G.; MATSUOKA, S. Inserção profissional de professores iniciantes: desafios e descobertas. In: CONGRESSO NACIONAL DE EDUCAÇÃO, 12., 2015, Curitiba. Anais [...]. Curitiba, PR: PUCPR, 2015. p. 37255- 37265. Disponível em:

https://educere.bruc.com.br/arquivo/pdf2015/17387_8838.pdf. Acesso em: 18 jul. 2020.

TARDIF, M.; RAYMOND, D. Saberes, tempo e aprendizagem do trabalho no magistério. Educação \& Sociedade, ano 21, n. 73, p. 209-244, dez. 2000. Disponível em: https://www.scielo.br/pdf/es/v21n73/4214. Acesso em: 18 jul. 2020. 
TEUBER, M. Relações entre Ensino, Práticas Artísticas e Pesquisa: princípios didáticos para a formação de professores de Artes Visuais. 2016. Tese (Doutorado) - Universidade Federal do Paraná, Curitiba, 2016. Disponível em: https://acervodigital.ufpr.br/handle/1884/51727. Acesso em: 18 jul. 2020.

VAILLANT, D.; MARCELO GARCÍA, C. Ensinando a ensinar. As quatro etapas de uma aprendizagem. Curitiba: Editora Universidade Tecnológica Federal do Paraná, 2012.

\section{Como referenciar este artigo}

AFONSECA, T. S.; NASCIMENTO, M. G. C. A. Perfil dos professores de artes plásticas ingressantes na rede municipal do Rio de Janeiro e seu olhar sobre sua inserção profissional. Revista Ibero-Americana de Estudos em Educação, Araraquara, v. 16, n. 3, p. 1898-1913, jul./set. 2021. e-ISSN: 1982-5587. DOI: https://doi.org/10.21723/riaee.v16i3.14071

Submetido em: 19/08/2020

Revisões requeridas em: 15/09/2020

Aprovado em: 10/10/2020

Publicado em: 01/07/2021 